\title{
Lung resection in cystic fibrosis patients with localised pulmonary disease
}

\author{
J Lucas, G J Connett, R Lea, C J Rolles, J O Warner
}

\begin{abstract}
The results of lobar resection to treat severe localised bronchiectasis in six children with cystic fibrosis are described. Sustained clinical improvements occurred in children undergoing this surgical approach to treatment. Detailed assessment and intensive preoperative and postoperative medical treatment are essential to a favourable outcome in carefully selected patients.

(Arch Dis Child 1996; 74: 449-451)
\end{abstract}

Keywords: cystic fibrosis, lobectomy.

Respiratory complications are the most common cause of morbidity and mortality among children with cystic fibrosis. Typically there is multifocal pulmonary involvement, but in a small number of cases severe disease is localised to one lobe and amenable to surgical resection. This has been recognised for many years. In 1972 Mearns reviewed 23 children with cystic fibrosis who were treated by pulmonary resection and reported a favourable outcome in the majority of cases. ${ }^{1}$ Subsequent papers from American centres have described the surgical treatment of persistent localised infection, haemoptysis, and bronchopleural fistula in cystic fibrosis. ${ }^{2-4}$ Many centres in the United Kingdom do not recommend surgery to treat localised disease in cystic fibrosis, fearing that the operative procedure might cause significant deterioration in wellbeing and lung function. This has not been our experience. In this paper we describe our use of pulmonary resection to treat localised bronchiectasis in six cystic fibrosis children over a six year period.

In all cases preoperative assessments included ventilation scans and computerised tomography (CT) scans to characterise the anatomical distribution of functioning lung and to determine the extent of bronchiectatic damage. Those with severe localised disease and little or no evidence for bronchiectasis elsewhere were offered surgery. Children were admitted to hospital for two weeks before operation and received intensive physiotherapy and intravenous antibiotics. Physiotherapy and suctioning were carried out immediately after the operation, before extubation. Close attention was paid to postoperative analgesia, and all children were mobilised as soon as possible. We describe the individual case histories and discuss the place of surgical resection in the modern management of cystic fibrosis. Details of preoperative and postoperative lung function and growth indices are shown in the table.

\section{Case 1}

Cystic fibrosis was diagnosed by sweat test following presentation with left lower lobe pneumonia at the age of 14 months. Despite aggressive inpatient treatment with intravenous and inhaled antibiotics, physiotherapy, oral steroids, and a suctioning bronchoscopy she remained dyspnoeic and failed to thrive over the next six months. Chest $x$ ray showed persistent left lower lobe consolidation. Left lower lobectomy was performed at the age of 20 months. She made an uneventful recovery and has not required any further hospital admissions. She is now aged $51 / 2$ years old and has a normal exercise capacity and normal lung function.

\section{Case 2}

This patient presented at 3 years of age with failure to thrive, rectal prolapse, and chronic productive cough. There were extensive radiological changes affecting the right upper lobe. Initial management included admissions every four to six months for intensive nutritional care, physiotherapy, and intravenous antibiotics. Improvements made during each admission were not sustained and respiratory symptoms increased. Right upper lobe changes progressed in spite of treatment and at 7 years of age chest $x$ ray showed advanced bronchiectatic changes in this area and Dr G J Connett.

Accepted 22 January 1996

Lung function and growth data

\begin{tabular}{|c|c|c|c|c|c|c|c|c|c|c|c|}
\hline \multirow[b]{2}{*}{ No } & \multirow{2}{*}{$\begin{array}{l}\text { Age at } \\
\text { diagnosis }\end{array}$} & \multirow{2}{*}{$\begin{array}{l}\text { Age at } \\
\text { operation }\end{array}$} & \multirow[b]{2}{*}{ Surgery } & \multicolumn{2}{|c|}{ FEV1 (\% predicted) } & \multicolumn{2}{|c|}{ FVC (\% predicted) } & \multicolumn{2}{|c|}{ Weight (SDS score) } & \multicolumn{2}{|c|}{ Height (SDS score) } \\
\hline & & & & Preop & Postop ${ }^{\star}$ & Preop & Postop ${ }^{\star}$ & Preop & Postop & Preop & Postop \\
\hline $\begin{array}{l}1 \\
2 \\
3 \\
4 \\
5 \\
6\end{array}$ & $\begin{array}{r}1 \text { y } 2 \mathrm{~m} \\
3 \text { y } 2 \mathrm{~m} \\
10 \mathrm{~m} \\
1 \mathrm{~m} \\
3 \text { y } 6 \mathrm{~m} \\
5 \mathrm{~m}\end{array}$ & 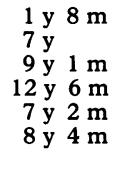 & $\begin{array}{l}\text { Left lower lobectomy } \\
\text { Right upper lobectomy } \\
\text { Right upper lobectomy } \\
\text { Right upper lobectomy } \\
\text { Right upper lobectomy } \\
\text { (1) Right lower lobectomy } \\
\text { (2) Right middle lobectomy }\end{array}$ & $\begin{array}{l}\text { Not done } \\
60 \% \\
85 \% \\
58 \% \\
51 \% \\
71 \%\end{array}$ & $\begin{array}{l}94 \% \\
75 \% \\
76 \% \\
59 \% \\
46 \% \\
83 \%\end{array}$ & $\begin{array}{l}\text { Not done } \\
76 \% \\
103 \% \\
66 \% \\
74 \% \\
77 \%\end{array}$ & $\begin{array}{l}91 \% \\
87 \% \\
94 \% \\
66 \% \\
71 \% \\
83 \%\end{array}$ & $\begin{array}{r}-1 \cdot 13 \\
-2 \cdot 63 \\
0 \cdot 29 \\
-3 \cdot 52 \\
-3 \cdot 42 \\
-1 \cdot 12\end{array}$ & $\begin{array}{r}0 \cdot 03 \\
-2 \cdot 63 \\
-0 \cdot 09 \\
-2 \cdot 53 \\
-4 \cdot 46 \\
-0.46\end{array}$ & $\begin{array}{r}0.40 \\
-2 \cdot 11 \\
-0.66 \\
-2 \cdot 50 \\
-2 \cdot 11 \\
-2 \cdot 03\end{array}$ & $\begin{array}{r}0.63 \\
-2.23 \\
-0.97 \\
-2.07 \\
-2.33 \\
-2.03\end{array}$ \\
\hline
\end{tabular}

Preop = preoperative; Postop $=$ postoperative

^Lung function, height, and weight measurements were recorded immediately preoperatively and approximately 6 months postoperatively except for postoperative lung function in case 1, which was recorded when she was aged 5 years. Lung function measurements were recorded after inhalation of bronchodilators. 


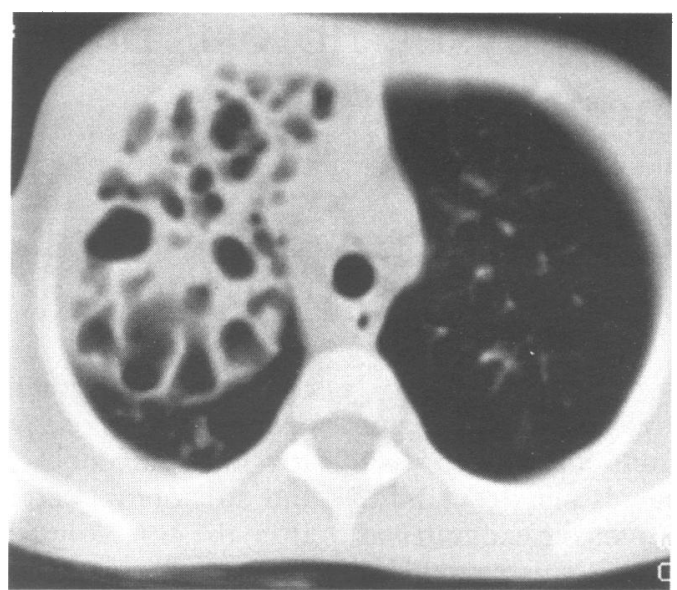

Figure 1 Preoperative computerised tomography scan of case 2.

increased peribronchial thickening elsewhere. A CT scan confirmed bronchiectatic destruction of the right upper lobe but normal appearances throughout the rest of the lungs (fig 1). She underwent right upper lobectomy and made an uneventful recovery. At six months follow up she is no longer producing sputum.

\section{Case 3}

This patient presented at the age of 10 months with respiratory symptoms. She was well for the next two years but subsequently developed a persistent cough and was chronically productive of green sputum. Chest $x$ ray showed patchy consolidation in the right upper lobe and crackles persisted in this area despite appropriate antibiotic treatment. Increasing respiratory symptoms were improved after the introduction of regular three monthly intravenous antibiotics. At 9 years of age she was increasingly productive of large amounts of dark green sputum and required antibiotics more often. Chest $x$ ray showed extensive bronchiectasis of the right upper lobe (fig 2). CT confirmed normal parenchyma elsewhere.

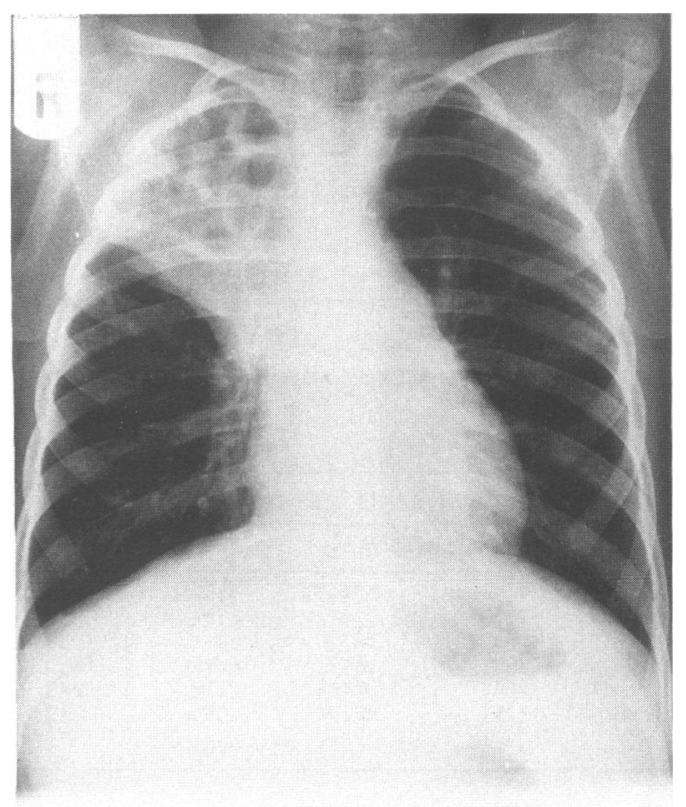

Figure 2 Preoperative chest $\mathrm{x}$ ray of case 3.
At 9 years of age she underwent right upper lobectomy. A postoperative chest $x$ ray is shown in fig 3. A small pneumothorax resolved after conservative management. She required one course of intravenous antibiotics six weeks after surgery and since then has remained extremely well. At six months follow up she has occasional coughing after exercise and is no longer producing sputum.

\section{Case 4}

This patient was diagnosed shortly after presentation at birth with meconium ileus. She was referred to the regional service at 5 years of age. When first seen she was marasmic. Height and weight were $7 \mathrm{~cm}$ and $5 \mathrm{~kg}$ below the $3 \mathrm{rd}$ centiles. There was digital clubbing, marked volume loss, and extensive cystic changes in the right upper lobe. Respiratory symptoms were controlled after the introduction of good physiotherapy techniques, prophylactic antibiotics, and regular intravenous treatment. Growth measurements increased to the 3rd centile over the next two years. At 11 years she developed increasingly severe respiratory symptoms and weight loss. A CT scan confirmed complete destruction of the right upper lobe with less marked bronchiectatic change elsewhere. Right upper lobectomy was performed with good postoperative recovery. At eight months follow up she rarely coughs and produces small amounts of pale sputum.

\section{Case 5}

This patient was diagnosed aged $3 \frac{1}{2}$ years after presentation with right upper lobe collapse. She was referred to the regional centre six months later and received intensive intravenous antibiotics, physiotherapy, and a suctioning bronchoscopy. This brought about increased aeration of her right upper lobe but there was persistent atelectasis of the posterior segment. Continuing respiratory symptoms were minimal but she remained regularly

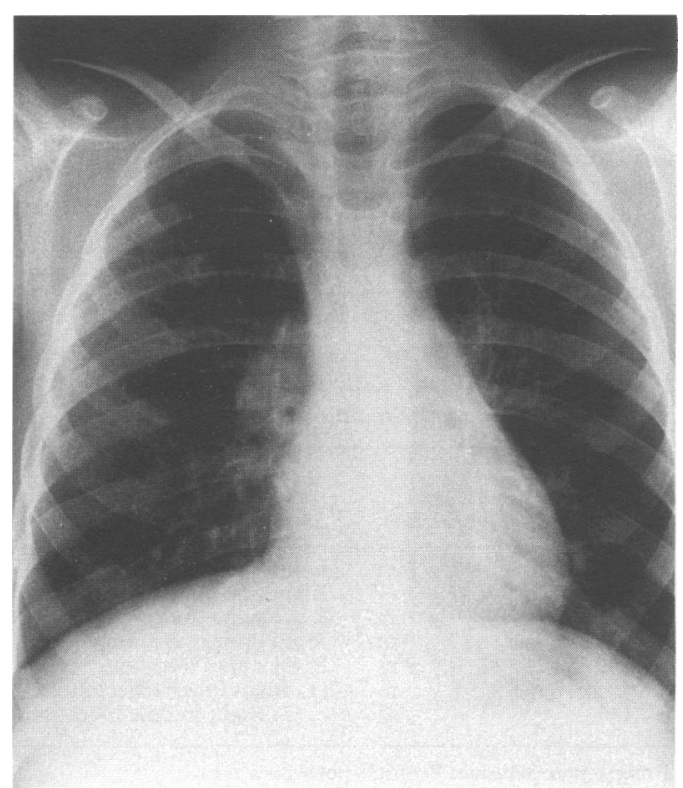

Figure 3 Postoperative chest $\mathrm{x}$ ray of case 3. 
productive of sputum. Nutritional status was poor because of persistent anorexia. Detailed reassessment at 7 years of age revealed complete destruction of the right upper lobe, which was resected. Postoperatively she has a significant increase in exercise capacity and is no longer regularly producing sputum. Her appetite remains poor.

\section{Case 6}

This patient was diagnosed with cystic fibrosis at 5 months because of respiratory symptoms. Recurrent chest infections caused intermittent radiological changes in the right upper and lower lobes for the next 18 months, but cleared. He remained well until aged 4 years, when he developed increasingly frequent respiratory symptoms with right lower lobe infiltrates on chest $x$ ray. At 7 years he was requiring intravenous antibiotics six weekly. Because of the increasing severity of symptoms and localised disease on chest $x$ ray he was referred for right lower lobectomy. Postoperatively he developed a tension pneumothorax. This was treated with closed thoracotomy chest tube drainage but his condition deteriorated. Repeat thoracotomy identified an infarcted right middle lobe which was resected. At three years follow up he is much less productive of sputum and normally active. He receives elective intravenous antibiotics three-monthly. His previously severe finger clubbing has significantly improved.

\section{Discussion}

We have carried out surgical resections in 6 children between 1989-1995. Our clinic currently sees 180 children under full or shared care arrangements and there are approximately 200 other CF children within the region with access to our centre. Isolated lobar abnormalities are relatively rare in CF and their frequency in our clinic would seem to agree with that reported elsewhere. ${ }^{4}$

It was reassuring to discover that lung function was maintained or improved in most cases after surgery. This was not the case in one series which included children with radiographic evidence of diffuse as well as severe localised disease and preoperative lung function less than $50 \%$ of predicted. ${ }^{3}$ Results in this group were variable. Detailed imaging in our series ensured that bronchiectasis was confined to the resected lobes. Examination of excised lung confirmed that the resected tissue was performing no useful function in any of the cases.

All patients were colonised with $P$ aeruginosa preoperatively. Subsequent cultures showed continued colonisation in all patients except Nos 1 and 6, who have remained clear of $P$ aeruginosa for five years and six months respectively following surgery. We cannot state whether surgery has increased long term survival, but quality of life was undoubtedly improved in all cases. Our expectation is that the removal of infected, inflamed tissue will limit the spread of bacterial pathogens to other lung areas.

More aggressive early treatment with new agents such as DNAse might have prevented progression to severe bronchiectasis. However, none of our cases had received this drug and four of the children would not have fulfilled local criteria for its use up to the time of their operations. Four of the children already had advanced lung damage when first seen at our centre. Earlier diagnosis and treatment through neonatal screening might have prevented their need for surgery.

Our results suggest that surgical resection is a worthwhile option in selected children who have severe localised symptomatic bronchiectasis and a poor response to medical treatment. Surgery is not a contraindication to lung transplantation although there is an increased risk of bleeding. ${ }^{5}$ Detailed assessment in a regional centre is necessary to identify those children who might benefit from this unusual approach. Intensive preoperative and postoperative care are essential to the good outcomes described.

1 Mearns MB, Hodson CJ, Jackson ADM, et al. Pulmonary resection in cystic fibrosis. Arch Dis Child 1972; 47: resection

2 Smith MB, Hardin WD, Dressel DA, Beckerman RC, Moyniham PC. Predicting outcome following pulmonary resection in cystic fibrosis patients. F Pediatr Surg 1991; 26: 655-9.

3 Marmon L, Schidlow D, Palmer J, Rohinton K, Balsara K, Dunn JM. Pulmonary resection for complications of cystic fibrosis. F Pediatr Surg 1983; 18: 811-5.

4 Stern RC, Boat TF, Orenstein DM. Treatment and prognosis of lobar and segmental atelectasis in cystic fibrosis. Am Rev Resp Dis 1978; 118: 821.

5 Bidstrup BP, Royston D, Sapsford RN, Taylor KM. Reduction in blood loss and blood use after cardiopulmonary bypass with high dose aprotinin (Trasylol). pulmonary bypass with high dose aprotin
$\mathcal{f}$ Thorac Cardiovasc Surg 1989; 97: 364-72. 